\title{
The renin-angiotensin system and diabetes: An update
}

\author{
Antônio Ribeiro-Oliveira Jr' \\ Anelise Impeliziere \\ Nogueira' \\ Regina Maria Pereira ${ }^{2}$ \\ Walkiria Wingester Vilas \\ Boas $^{3}$ \\ Robson Augusto Souza dos \\ Santos ${ }^{4}$ \\ Ana Cristina Simões e Silva ${ }^{5}$
}

'Laboratório de Endocrinologia, Departamento de Clínica Médica, ${ }^{2}$ Departamento de Ciências Biológicas, Centro Universitário de Belo Horizonte, UNIBH, Belo Horizonte, MG, Brazil; ${ }^{3}$ Hospital Life Center, Belo Horizonte, MG, Brazil; ${ }^{4}$ Laboratório de Hipertensão, Departamento de Fisiologia e Biofísica, Instituto de Ciências Biológicas, UFMG, Belo Horizonte, MG, Brazil; ${ }^{5}$ Departamento de Pediatria, Faculdade de Medicina, Universidade Federal de Minas Gerais (UFMG), Belo Horizonte, MG, Brazil

Correspondence: Ana Cristina Simões Silva

Avenida Bernardo Monteiro, 1300 apto I I 04, Bairro Funcionários,

Belo Horizonte, Minas Gerais,

Brazil, 30I50-28 I

Tel +553 I 78148682

Fax +55 3I 32275555

Email acssilva@hotmail.com,

ana@medicina.ufmg.br

\begin{abstract}
In the past few years the classical concept of the renin-angiotensin system (RAS) has experienced substantial conceptual changes. The identification of the renin/prorenin receptor, the angiotensin-converting enzyme homologue ACE2 as an angiotensin peptide processing enzyme, Mas as a receptor for Ang-(1-7) and the possibility of signaling through ACE, have contributed to switch our understanding of the RAS from the classical limited-proteolysis linear cascade to a cascade with multiple mediators, multiple receptors, and multi-functional enzymes. In this review we will focus on the recent findings related to RAS and, in particular, on its role in diabetes by discussing possible interactions between RAS mediators, endothelium function, and insulin signaling transduction pathways as well as the putative role of ACE2-Ang-(1-7)Mas axis in disease pathogenesis.
\end{abstract}

Keywords: renin-angiotensin system, diabetes, angiotensin II, angiotensin-(1-7), insulin, endothelium

\section{Introduction}

In a classical view, the renin-angiotensin system (RAS) is considered an endocrine system whose active metabolite, the angiotensin II (Ang II), is produced by enzymatic sequential cleavage from the angiotensinogen substratum of hepatic origin (Weber et al 2001; Zaman et al 2002). In the bloodstream, the renin, a highly specific protease, converts the circulating angiotensinogen into the decapeptide Ang I, which, in turn is converted to Ang II by the angiotensin-converting enzyme (ACE) action (Weber et al 2001; Zaman et al 2002). This enzyme also inactivates bradykinin (BK) and is highly found in the endothelial cells membranes of the pulmonary circulation (Weber et al 2001; Zaman et al 2002; Carey and Siragy 2003a).

In the past few years the classical concept of the RAS has experienced substantial conceptual changes. Although this system is known for decades, recent discoveries in cellular and molecular biology, as well as cardiovascular and renal physiology, have introduced larger understanding about its function in physiological situations and in several diseases (Carey and Siragy 2003a; Chappell et al 2004; Simões e Silva et al 2006a; Santos and Ferreira 2007; Chappell 2007).

One of the most relevant conceptual changes in our understanding of the RAS was the discovery of local or tissue RAS (Miyazaki and Takai 2006; Paul et al 2006). A local system is characterized by the presence of RAS components, such as angiotensinogen, processing enzymes, angiotensins, and specific receptors at tissue level. In the 70's, Ganten and colleagues (1971) demonstrated, for the first time, that all RAS's components could be produced locally in several organs and tissues. The local RAS has been found in the heart, blood vessels, kidney, adrenal gland, pancreas, central nervous system, reproductive system, lymphatic and adipose tissue (Nielsen et al 2000; Sernia 2001; Lavoie and Sigmund 2003; Spät and Hunyady 2004). The local systems appear to be regulated independently of the circulatory RAS but can also interact with 
the latter. In this way, local RAS's effects could occur in the cell that produces the peptides (intracrine and autocrine functions), in adjacent cells (paracrine function) or through the bloodstream to a specific organ or tissue (endocrine function) (Miyazaki and Takai 2006; Paul et al 2006). The main importance of tissue RAS is linked to local regulatory mechanisms that contribute to a great number of homeostatic pathways, including cellular growth, extracellular matrix formation, vascular proliferation, endothelium function and apoptosis (Miyazaki and Takai 2006; Paul et al 2006).

Other important landmarks for the new concept of RAS were the characterization of angiotensin-(1-7) [Ang-(1-7)] as a biological active metabolite of RAS (Simões e Silva et al 2006a; Santos and Ferreira 2007), the Ang IV receptor as an insulin-regulated aminopeptidase (IRAP) (Albiston et al 2001), the renin/prorenin receptor (Nguyen et al 2002), the ACE homologue ACE2 as an angiotensin peptide processing enzyme (Donoghue et al 2000; Tipnis et al 2000), Mas as a receptor for Ang-(1-7) (Santos et al 2003), and the possibility of signaling through ACE (Kohlstedt et al 2004). These discoveries have contributed to switch our understanding of the RAS from the classical limited-proteolysis linear cascade to a cascade with multiple mediators, multiple receptors, and multi-functional enzymes (Simões e Silva et al 2006a; Santos and Ferreira 2007; Chappell 2007) (Figure 1).

In regard to Ang-(1-7), the identification of ACE2 and Mas as a receptor implicated in its actions contributed to decisively establish this heptapeptide as a biologically active member of the RAS cascade. Most evidence supports a counter-regulatory role for Ang-(1-7) by opposing many Ang

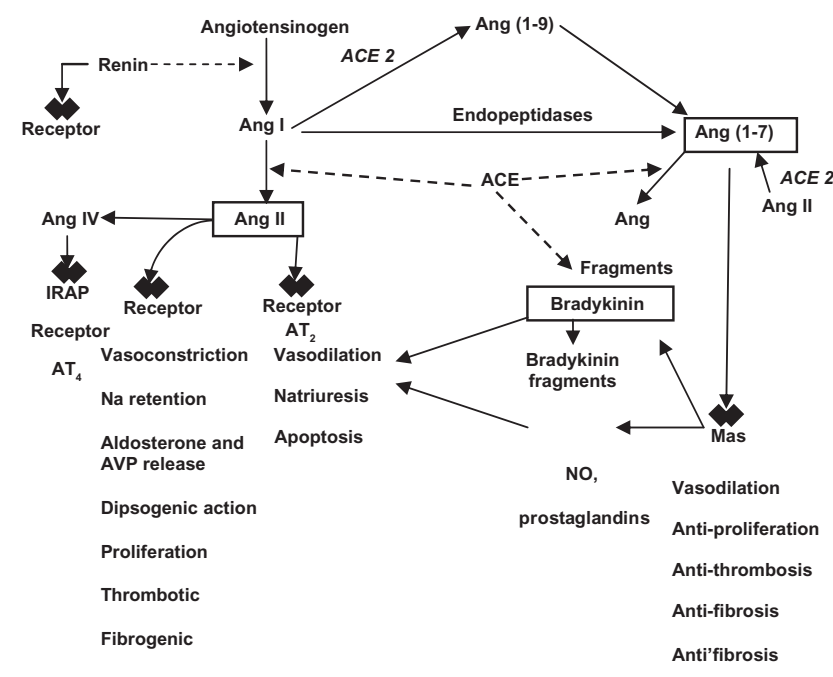

Figure I Novel components of the renin-angiotensin system and its interactions. Abbreviations: Ang, angiotensin, $\mathrm{AT}_{1}, \mathrm{AT}_{2}$, angiotensinergic receptors types $\mathrm{I}$ and 2; $\mathrm{NO}$, nitric oxide; $\mathrm{ACE}$, angiotensin-converting enzyme; $\mathrm{ACE} 2$, angiotensin-converting enzyme 2 .
II-AT $_{1}$ receptor-mediated actions, especially vasoconstriction and proliferation (Simões e Silva et al 2006a; Santos and Ferreira 2007; Chappell 2007). Furthermore, Ang-(1-7) has been associated to the physiopathology of several diseases such as hypertension (Luque et al 1996; Ferrario et al 1998; Simões e Silva et al 2004, 2006b, 2006c), pre-eclampsia (Merril et al 2002; Brosnihan et al 2004; Shah 2005), hypertrophic myocardial disease and congestive heart failure, myocardial infarct (Zisman et al 2003; Santos and Ferreira 2005), chronic renal diseases (Simões e Silva et al 2006b), hepatic cirrhosis (Paizis et al 2005; Pereira et al 2007; Herath et al 2007; Warner et al 2007), diabetic nephropathy (Carey and Siragy 2003b; Tikelis et al 2003; Kalantrina and Okusa 2006), and gestational diabetes (Nogueira et al 2007).

This review will summarize the current aspects of RAS, its role in diabetes, and its well-known and putative interactions with endothelium function and insulin signaling. Moreover, the importance of the RAS to diabetes prevention and its involvement on cardiovascular and renal events in diabetic patients will be discussed.

\section{New aspects of the RAS components \\ Angiotensinogen}

Angiotensinogen (AGT) is a glycoprotein of 452 aminoacids produced in the liver as well as in other tissues (including the heart, vessels, kidneys, and adipose tissue), which circulates as an inactive biological peptide. Through renin action, it is converted into Ang I, the precursor peptide in classical RAS cascade (Weber et al 2001).

The M235T polymorphism of the AGT gene is known to be associated with circulating and tissue AGT (Bloem et al 1995; Winkelmann et al 1999; Gumprecht et al 2000). However, the finding of genetic linkage between the AGT gene and hypertension in many studies and the presence of increased levels of plasma AGT in subjects with higher parental and personal blood pressure only support a role for increased synthesis of angiotensinogen in hypertension but do not explain how this translates into elevated blood pressure (Naber and Siffert 2004). One hypothesis is that the genetic increase in RAS activity due to the T235 allele of AGT may lead to greater formation of Ang II in cardiac, vascular, and renal tissues, predisposing to cardiovascular and renal damage (Winkelmann et al 1999; Gumprecht et al 2000).

\section{Renin}

Renin is an aspartyl protease enzyme produced by the juxtaglomerular apparatus of the kidney. This enzyme acts on 
AGT and forms the decapeptide Ang I. Renin is considered a key enzyme of the RAS due to the rate-limiting nature of its hydrolytic activity on the precursor AGT (Weber et al 2001; Zaman et al 2002).

In recent years, this view has acquired new and important features after the discovery of the renin/prorenin receptor by Nguyen and colleagues (2002). Thus, according to our new understanding of the role of renin within the RAS, it serves as an Ang II-generating enzyme through the limitedproteolysis process started by its action on AGT and it can act as an agonist of the RAS inducing signaling through its receptor. In addition, binding of renin to its receptor appears to increase its catalytic efficiency on its substrate. We are still searching for the biological and physiopathological implications of these actions, but there are suggestions that it may be implicated in target-organ lesion, especially in the kidney (Staessen et al 2006).

\section{Angiotensin-converting enzyme}

The key role of angiotensin-converting enzyme (ACE) within the RAS is well established since the pioneering work of Skeggs and colleagues (1956), which showed that ACE is the main Ang II-generating enzyme. About 40 years later, the action of ACE in the catabolism of Ang-(1-7) was clearly established (Deddish et al 1998). As shown in Figure 1, by forming the potent vasoconstrictor Ang II and inactivating the vasodilator Ang-(1-7), ACE plays a central role as a pressor enzyme. Another action outside the RAS, the inactivation of the vasodilator BK, further strengthens the role of ACE as a pro-hypertensive enzyme.

However, the role of ACE is not restricted to its hydrolytic activity. Fleming and colleagues (Kohlstedt et al 2004) have identified a new action of ACE: the out-in signaling. According to this novel view, upon binding by bradykinin (BK) and ACE inhibitors (ACEi), ACE is phosphorylated at the amino acid Ser1270 and triggers a signal cascade, which was able to increase ACE and COX-2 synthesis. In addition, the signaling through ACE was described in adipocytes and pre-adipocytes (Kohlstedt et al 2004).

\section{Angiotensin-converting enzyme 2}

In 2000, two independent groups (Donoghue et al 2000; Tipnis et al 2000) identified a new enzyme homologue of ACE, which they called angiotensin-converting enzyme 2 (ACE2) (Donoghue et al 2000) and captopril insensitive carboxypeptidase (Tipnis et al 2000). This enzyme shows a homology of about $42 \%$ with ACE, but different biochemical activities, being highly specific for angiotensin cleavage.
For example, in contrast to classical ACE, ACE2 does not metabolize BK.

In the original work of Donoghue and colleagues (2000), ACE2 was described as having as a primary activity the hydrolysis of Ang I, generating Ang-(1-9), serving as an indirect pathway to generate Ang II. However, this interpretation was challenged by the demonstration that Ang II was the preferable substrate for ACE2 (Tipnis et al 2000; Vickers et al 2002). Indeed, the catalytic efficiency of ACE2 against Ang II is 400-fold higher than for Ang I and leads to Ang-(1-7) formation (Rice et al 2004). It is also functionally remarkable that ACE2 is the main enzyme for Ang-(1-7) generation in many tissues (Rice et al 2004; Ferrario et al 2005).

Taking into account the enzymatic properties of the two ACEs and of the two main RAS mediators, Ang II and Ang-(1-7), we can make out a new vision of the RAS. In this novel concept, the RAS can be seen as a dual function system in which the vasoconstrictor/proliferative or vasodilator/antiproliferative actions are primarily driven by the ACE/ACE2 balance (Simões e Silva et al 2006a; Santos and Ferreira 2007; Chappell 2007; Warner et al 2007). According to this concept, an elevated ACE activity concomitant with a reduced ACE2 activity will lead to increased Ang II generation and increased catabolism of Ang-(1-7)-favoring vasoconstriction, while the opposite profile (elevated ACE2 activity with reduced ACE activity) will decrease Ang II levels by converting it into Ang-(1-7), which, in turn, promotes vasodilation (Simões e Silva et al 2006a; Santos and Ferreira 2007; Chappell 2007; Warner et al 2007).

\section{Angiotensin II}

Ang II was isolated in 1940 by Braun-Menendez and colleagues (1940) and Page and Helmer (1940) and was firstly characterized as a potent vasoconstrictor that increases peripheral vascular resistance and consequently elevates arterial pressure. In situations of extracellular fluid volume contraction, Ang II reduces renal sodium excretion via alterations in renal hemodynamics, direct enhancement of proximal tubule sodium bicarbonate reabsorption, and aldosteronemediated increases in late distal tubule and cortical collecting duct reabsorption (Hall 1991; Ichikawa and Harris 1991; Hall et al 1999; Brewster and Perazella 2004). Ang II also increases thirst, salt appetite, and intestinal sodium absorption, all of which increase the extracellular fluid volume. In this context, the RAS was initially defined as an endocrine system in which circulating Ang II regulates blood pressure and electrolyte balance via its actions on vascular tone, 
aldosterone secretion, renal sodium handling, thirst, water intake, sympathetic activity, and vasopressin release.

Additional experimental studies as well as clinical trials using ACE inhibitors and Ang II type 1 ( $\mathrm{AT}_{1}$ ) receptor blockers have shown that the actions of this system extend far beyond blood pressure control and electrolyte balance (Ferrario et al 2004). It has become clear that the deleterious actions of RAS on cardiovascular remodeling and renal function account for the beneficial effects of the ACE inhibitors and $\mathrm{AT}_{1}$ receptor blockers in patients with hypertension, left ventricular hypertrophy, heart failure, and diabetic nephropathy (Ferrario et al 2004). However, besides circulating RAS, Ang II as well as other RAS mediators can also be locally produced and exert paracrine, intracrine, and autocrine effects (Myiazaki and Takai 2006). One of the first evidence for the tissue formation of Ang II came from studies on angiotensin metabolism in sheep (Fei et al 1980). The octapeptide was subsequently found to be produced in numerous tissues, including the adrenal, brain, heart, kidney, vasculature, adipose tissue, gonads, pancreas, prostate, eye, and placenta (Nielsen et al 2000; Sernia 2001; Lavoie and Sigmund 2003; Spät and Hunyady 2004; Navar and Nishiyama 2004; Brewster and Perazella 2004). Further investigations proposed that in the circulating RAS, renin originating from the kidney is a rate-limiting factor for Ang II generation in plasma, but in the vascular tissue, ACE and other peptidases such as chymase regulate Ang II generation (Myiazaki and Takai 2006). Although not all components of the classical RAS are synthesized locally in some tissues, alternative enzymatic pathways or the presence of the renin receptor, which binds to and activates circulating renin and prorenin (Nguyen et al 2002), may also permit local Ang II formation. In addition, the RAS is also able to exert intracrine effects due to the intracellular formation of Ang II $(\operatorname{Re} 2003$; Baker et al 2004). However, kinetic studies suggest that intracellular Ang II is largely derived from receptor-mediated uptake of the extracellular peptide (Danser 2003).

The cellular Ang II receptor was identified in 1974 as a high-affinity plasma membrane-binding site that is sensitive to guanyl nucleotides (Glossmann et al 1974). Later, distinct $\mathrm{AT}_{1}$ and $\mathrm{AT}_{2}$ receptor subtypes were identified by selective ligands (De Gasparo et al 2000) and were subsequently characterized as seven transmembrane receptors by molecular cloning (Murphy et al 1991; Sasaki et al 1991; Kambayashi et al 1993; Mukoyama et al 1993). Thus, Ang II mediates effects via complex intracellular signaling pathways that are stimulated following binding of the peptide to its cellsurface receptors, $\mathrm{AT}_{1}$ and $\mathrm{AT}_{2}$ (Murphy et al 1991; Touyz and Schiffrin 2000). In humans, $\mathrm{AT}_{1}$ receptor is widely expressed in blood vessels, heart, kidney, adrenal glands, and liver, whereas $\mathrm{AT}_{2}$ receptor is present mainly in fetal tissue, decreasing rapidly after birth, with relatively low amounts normally expressed in adult tissue. The G protein-coupled $\mathrm{AT}_{1}$ receptor mediates the known physiological and pathological actions of Ang II and undergoes rapid desensitization and internalization after agonist stimulation. In contrast, the $\mathrm{AT}_{2}$ receptor does not exhibit the latter features and acts mainly through $\mathrm{G}_{\mathrm{i}}$ and tyrosine phosphatases to exert predominantly inhibitory actions on cellular responses mediated by the $\mathrm{AT}_{1}$ receptor and growth factor receptors (Nouet and Nahmias 2000; Hunyady and Catt 2006). For example, both receptors play a role in regulating vascular smooth muscle cell (VSMC) function, although they differ in their actions. While the $\mathrm{AT}_{1}$ receptor is associated with growth, inflammation and vasoconstriction, the $\mathrm{AT}_{2}$ receptor is generally associated with opposite actions stimulating apoptosis and vasodilatation (Touyz and Schiffrin 2000).

Animal models and clinical data have also helped to establish that inhibition of Ang II action in nonclassical target sites, such as immune cells, explains some of the unanticipated therapeutic effects of $\mathrm{ACE}$ inhibitors and $\mathrm{AT}_{1}$ receptor blockers (Ferrario et al 2004). Parallel studies on the molecular mechanism of action of Ang II have revealed that its main target, the $\mathrm{AT}_{1}$ receptor, is one of the most versatile members of the G protein-coupled receptor (GPCR) family (Hunyady and Catt 2006). Ang II exerts several cytokinelike actions via the $\mathrm{AT}_{1}$ receptor and can stimulate multiple signaling pathways, activate several growth factor receptors, and promote the formation of reactive oxygen species (ROS) and other proinflammatory responses (Hunyady and Catt 2006).

\section{Angiotensin-(I-7)}

Ang-(1-7) was regarded as an inactive component of the RAS for many years. However after the demonstration that Ang-(1-7) was the main product formed from Ang I through an ACE-independent pathway, in dog brain micro-punches homogenates (Santos et al 1988) and the demonstration that this heptapeptide was equipotent to Ang II to elicit vasopressin release from neurohyphophyseal explants (Schiavone et al 1988) and to decrease blood pressure upon microinjection into the nTS (Campagnole-Santos et al 1989), the importance of Ang-(1-7) within the RAS became increasingly evident.

Ang-(1-7) is formed from Ang II by prolylendopeptidase, prolyl-carboxipeptidase or ACE2 or directly from Ang I through hydrolysis by prolylendopeptidase and 
endopeptidase 24.11 and it is metabolized by ACE to Ang(1-5) (Donoughue et al 2000; Tipnis et al 2000; Chappell et al 2004; Rice et al 2004). ACE inhibitors elevate plasma Ang(1-7) concentrations by both increasing Ang I, the substrate for Ang-(1-7), as well as by preventing Ang-(1-7) degradation (see Figure 1). Ang-(1-7) is present in the circulation and in many tissues including heart, blood vessels, kidney and liver (Simões e Silva et al 2006a; Santos and Ferreira 2007; Chappell 2007).

The recent identification of ACE2 which forms Ang-(1-7) from Ang II (Donoughue et al 2000; Tipnis et al 2000), and the G-protein coupled receptor Mas as an Ang-(1-7) receptor (Santos et al 2003) have provided biochemical and molecular evidence for the biological significance of the Ang-(1-7). In addition, the inhibitory effects of Ang-(1-7) on Ang II-induced vasoconstriction, and its growth-inhibitory, antiarrhythmogenic and antithrombogenic effects imply a counter regulatory role for this angiotensin within the RAS and suggest that this may be a potential target for development of new drugs (Simões e Silva et al 2006a; Santos and Ferreira 2007; Chappell 2007).

In this regard, recent studies suggest that, at least in part, the beneficial effects of ACE inhibitors in heart and kidney diseases may be attributed to Ang-(1-7) (Simões e Silva et al 2006a; Santos and Ferreira 2007). These findings are in agreement with the hypothesis that the RAS is capable to self-regulate its activity through the formation of Ang-(1-7). In addition, Kostenis and colleagues (2005) recently demonstrated that the Ang-(1-7) G-protein coupled receptor Mas can hetero-oligomerize with $\mathrm{AT}_{1}$ receptor and by so inhibit the actions of Ang II. Indeed, Mas receptor acts in vivo as an antagonist of the $\mathrm{AT}_{1}$ receptor (Kostenis et al 2005). We currently believe that RAS can act through two opposite arms: the major one responsible for the main actions of this system is constituted by the ACE-Ang II-AT receptor $_{1}$ axis and the other, a counterregulatory arm, is formed by the ACE2-Ang-(1-7)-Mas axis (Simões e Silva et al 2006a; Santos and Ferreira 2007).

\section{Angiotensin III}

Ang III is generated from the metabolism of Ang II by aminopeptidase A, which cleaves the Asp1-Arg2 bound. Ang III is a biologically active peptide of the RAS whose effects are essentially similar to those observed for Ang II though less potent. Ang III enhances blood pressure, vasopressin release, and thirst when it is centrally administrated (Cesari et al 2002). Ang III infusion increases blood pressure in healthy volunteers and hypertensive patients (Suzuki et al 1984) as well as augments aldosterone release (Plovsing et al 2003). Ang III does not affect renal function in humans (Plovsing et al 2003), but it induces natriuresis probably through $\mathrm{AT}_{2}$ receptors stimulation in $\mathrm{AT}_{1}$ receptor-blocked rats (Padia et al 2006). In addition, in cultured renal cells this peptide stimulates the expression of many growth factors, proinflammatory mediators, and extracellular matrix proteins (RuizOrtega et al 2000). Ang III normally binds to $\mathrm{AT}_{1}$ and with more affinity to $\mathrm{AT}_{2}$ receptors (Padia et al 2007). However, it is still not established whether these effects of Ang III are due to direct action of this peptide at angiotensins ' receptors or they are mediated by smaller peptides formed as a consequence of its degradation.

\section{Angiotensin IV}

Ang IV was generated by the enzyme aminopeptidase $\mathrm{N}$, which removes the amino acid arginine from the N-terminus of Ang III sequence. Alternatively, this angiotensin fragment can be also formed directly from Ang II by the enzyme D-aminopeptidase. Central administration of Ang IV markedly enhances learning and memory in normal rodents and reverses memory deficits observed in animal models of amnesia (Chay et al 2004; Braszko et al 2006). In the kidney, Ang IV increases renal cortical blood flow without altering systemic blood pressure and decreases $\mathrm{Na}^{+}$transport in isolated renal proximal tubules (Chay et al 2004). On the other hand, other studies have shown that this peptide can decrease total and regional renal blood flow in rats ( $\mathrm{Li}$ et al 2006). It has been reported that Ang IV induces vasodilation in preconstricted endothelium-intact but not endotheliumdenuded pulmonary artery through a specific binding site that is blocked by divalinal (Chen et al 2000). In addition, this peptide increases endothelial NO synthase activity and cellular cGMP content in porcine pulmonary arterial endothelial cells (Patel et al 1998). In the heart, Ang IV reduced left ventricular pressure-development and ejection capabilities but increased the sensitivity of pressure development during the systole and speeded relaxation (Slinker et al 1999).

Most Ang IV actions are mediated by a specific binding site called $\mathrm{AT}_{4}$ receptor. This receptor is found in many organs such as brain, adrenal gland, kidney, lung, and heart and it mediates the majority of Ang IV actions (Chay et al 2004; Albiston et al 2007). However, in some circumstances, Ang IV can induce its effects by interacting with $\mathrm{AT}_{1}$ receptor ( $\mathrm{Li}$ et al 2006). It is important to mention that Ang IV is not the only ligand for $\mathrm{AT}_{4}$ receptor, since other peptides such as LVV-hemorphin 7 can bind to this receptor (Albsiton et al 2004). The $\mathrm{AT}_{4}$ receptor has been also identified 
as the transmembrane enzyme, insulin-regulated membrane aminopeptidase (IRAP) (Albiston et al 2001). IRAP is a type II integral membrane spanning protein belonging to the M1 family of aminopeptidases and is predominantly found in GLUT4 vesicles in insulin-responsive cells. Three hypotheses for the memory-potentiating effects of the $\mathrm{AT}_{4}$ receptor/IRAP ligands, Ang IV and LVV-hemorphin 7, are proposed: acting as potent inhibitors of IRAP, they may prolong the action of endogenous promnestic peptides; they may modulate glucose uptake by modulating trafficking of GLUT4; IRAP may act as a receptor, transducing the signal initiated by ligand binding to its $\mathrm{C}$-terminal domain to the intracellular domain that interacts with several cytoplasmic proteins (Chay et al 2004; Albiston et al 2007). However, the precise meaning of this finding remains to be elucidated.

\section{Other angiotensin peptides}

The physiological relevance of other angiotensin peptides is still unclear. Indeed, many studies have been showing the presence of these angiotensins in diverse clinical conditions. It is possible that the formation of other angiotensins could be an alternative mechanism to override different levels of RAS blockade, thus interfering with the action of ACE inhibitors or $\mathrm{AT}_{1}$ receptor blockers.

Recent reports have attributed some biological actions to the smaller fragment of the RAS as the Ang-(3-7). A result of the degradation of Ang-(1-7), Ang II, and Ang IV by aminopeptidase or carboxypeptidase, it is believed that this angiotensin plays important role in the brain (Karwowska-Poleska et al 1997) and kidney (Handa 1999). Indeed, Ang-(3-7) has an affinity for $\mathrm{AT}_{4}$ receptors that did differ from Ang IV.

The issue whether Ang-(1-9) itself has direct biological effects or whether its supposed actions are elicited by generation of different metabolites, especially Ang-(1-7), remains unsolved. In some pathological conditions, its concentration changes significantly, indicating that it could be involved in those diseases (Ocaranza et al 2006). Ang-(1-9) can be formed direct from Ang I through catalytic action of ACE2 and it is metabolized by ACE and NEP to generate Ang(1-7) (Rice et al 2004). It has been reported that this peptide enhances BK actions, increases NO and arachidonic acid release (Jackman et al 2002), and is involved in the regulation of platelet function (Mogielnicki et al 2003).

Ang A, also a novel angiotensin peptide, was firstly detected in plasma from healthy humans and in end-stage renal disease patients (Jankowski et al 2007). Ang A concentrations were less than $20 \%$ of the Ang II concentrations in healthy subjects, but the ratio of Ang A/Ang II has been shown as higher in end-stage renal disease patients. In a different way from other angiotensin fragments, Des[Asp $\left.{ }^{1}\right]-\left[\mathrm{Ala}^{1}\right]$-Ang II is generated by decarboxylation reaction instead of cleavage process. Thus, the first amino acid of the Ang II sequence (aspartic acid) is converted into alanine. Conventional enzyme immunoassays do not distinguish between Ang II and Ang A. Otherwise, these assays quantify the sum of Ang II and Ang A. Ang A has similar affinity to the $\mathrm{AT}_{1}$ receptor as Ang II, but a higher affinity to the $\mathrm{AT}_{2}$ receptor. However, its activity in in vitro preparations is lower when compared with Ang II. Indeed, Ang A is a less potent and only partial agonist at the $\mathrm{AT}_{1}$ receptor. On the other hand, due to its high affinity to the $\mathrm{AT}_{2}$ receptor, it could be an endogenous Ang II regulatory peptide (Jankowski et al 2007).

The demonstration of endogenous Ang-(1-12) in the rat may foretell renin-independent pathways that lead to the formation of biologically active peptides (Nagata et al 2006). Indeed, the peptide bond Tyr12-Tyr13 hydrolyzed to produce Ang-(1-12) from rat angiotensinogen is structurally distinct from the Leu10-Leu11 bond recognized by rat renin to form Ang I. Moreover, these bonds are also distinct for human angiotensinogen (Nagata et al 2006). Despite the absence of a functional effect attributed to Ang-(1-12), the processing to this intermediate peptide may comprise another level of RAS regulation.

Tables 1 and 2 summarize the results obtained by recent basic and clinical research on RAS.

\section{RAS and diabetes}

The association of the RAS with the endocrine system is particularly illustrated by the prominent role of Ang II in diabetes and metabolic syndrome. The frequent association of diabetes mellitus (DM) with hypertension, retinopathy, nephropathy, and cardiovascular disease has implicated the RAS in the initiation and progression of these disorders. This has been demonstrated by clinical trials in which RAS inhibitors significantly reduced the incidence of vascular complications in DM patients (UKPDS 1998; HOPE 2000; Brenner et al 2001; Lewis et al 2001; Parving et al 2001; Jandeleit-Dahm et al 2005). These improvements appear to result from protective actions upon skeletal muscle (Muller et al 1997; Frossard et al 2000) and pancreatic islets (Lupi et al 2006), and also from enhanced insulin sensitivity associated with decreased adipocyte size (Furuhashi et al 2004), as well as increased transcapillary glucose transport (Muller et al 1997; Frossard et al 2000). Ang II can also cause insulin resistance by interfering with the insulin-stimulated increase in insulin receptor substrate 1-associated PI3K activity (Folli et al 1999) (Figure 2). 
Table I Summary of recent basic research on renin-angiotensin system

Author
Abdalla et al 2000
Albiston et al 200I
Baker et al 2004
Benter et al 2008
Clark et al 2008
Donoghue et al 2000

Ferrario et al 2004

Fraga-Silva et al 2008

Furuhashi et al 2004

Gallagher et al 2004

Herath et al 2007

Jackman et al 2002

Jankowski et al 2007

Kohlstedt et al 2004

Kostenis et al 2005

Lau et al 2004

Lupi et al 2006

Maia et al 2004

Nagata et al 2006

Nguyen et al 2002

Paizis et al 2005

Pereira et al 2007

\section{Results/Interpretations}

$A T$, receptor and the bradykinin (B2) receptor also communicate directly with each other.

The AT(4) receptor is insulin-regulated aminopeptidase and possibly the AT(4) receptor ligands may exert their effects by inhibiting the catalytic activity of insulin-regulated aminopeptidase.

Losartan did not block the growth effects of Ang II, excluding the involvement of extracellular Ang II and the plasma membrane ATI receptor. These data demonstrate a previously unknown growth mechanism of Ang II in the heart.

Ang-(I-7) decreased the elevated levels of renal NADPH oxidase (NOX) activity and attenuated the activation of NOX-4 gene expression in the diabetic SHR kidney.

c-Jun N-terminal kinase mediates Ang II-specific astrocyte proliferation.

This study identifies ACE2 as the first known human homologue of ACE, an enzyme that plays a central role in vascular, renal, and myocardial physiology. In contrast to ACE, however, ACE2 is highly tissue-specific: whereas ACE is expressed ubiquitously in the vasculature, human ACE2 is restricted to heart, kidney, and testis.

Lisinopril augmented plasma levels and urinary excretion rates of Ang I and Ang-( I-7), while plasma Ang II was reduced with no effect on urinary Ang II. Losartan produced similar changes in plasma and urinary Ang-(I-7) but increased plasma Ang II without changing urinary Ang II excretion. This study revealed a role for ACE2 in Ang-(I-7) formation from Ang II in the kidney of normotensive rats as primarily reflected by the increased ACE2 activity measured in renal membranes from the kidney of rats given either lisinopril or losartan.

This study is the first to show the presence of Mas protein and specific binding for Ang- $(\mathrm{I}-7)$ in rat and mouse platelets. It also suggests that the Ang-(I-7) antithrombotic effect involves Mas-mediated NO release from platelets.

RAS blockade decreases adipocyte size in rats without change in epididymal \%fat pads accompanied by improvement in insulin sensitivity.

The results of this study suggest that Ang-(I-7) inhibits lung cancer cell growth through the activation of an angiotensin peptide receptor and may represent a novel chemotherapeutic and chemopreventive treatment for lung cancer.

RAS activation in chronic liver injury was shown to be associated with upregulation of ACE2, Mas and hepatic conversion of angiotensin II to angiotensin-( I-7) leading to increased circulatting angiotensin-( I-7).

The two derivatives of Ang I,Ang I-9, and Ang I-7, liberated by enzymes in heart tissues, were shown to enhance the local effects of kinins by augmenting $\mathrm{NO}$ and arachidonic acid release.

Ang $A$ was shown to be a novel human strong vasoconstrictive angiotensin-derived peptide. Plasma Ang $A$ concentration seems to be increased in end-stage renal failure. Because of its stronger agonism at the AT2 receptor, it is suggested that Ang A may modulate the harmful effects of Ang II.

ACE was shown to be involved in outside-in signaling in endothelial cells and "ACE signaling” was suggested to be an important cellular mechanism contributing to the beneficial effects of ACE inhibitors

This study showed that Mas can hetero-oligomerize with the ATI receptor and by so doing inhibit the actions of angiotensin II.This is a novel demonstration that a G-protein-coupled receptor acts as a physiological antagonist of a previously characterized receptor.

The data coming from this study indicate the existence of an islet angiotensin-generating system of potential importance in the physiological regulation of glucose-induced insulin secretion, thus diabetes mellitus.

RAS molecules were shown in human islets and their expression was sensitive to glucose concentration. ACE inhibitors, and in particular zofenoprilat, protected human islets from glucotoxicity and the effects of ACE inhibition were associated with decreased oxidative stress.

This study suggests that endogenous Ang-(I-7) and/ or an Ang-(I-7)-related peptide plays an important role in the BK potentiation by ACEl through a mechanism not dependent upon inhibition of ACE hydrolytic activity.

The identification of proangiotensin- 12 suggests a processing cascade of the RA system, different from the cleavage of angiotensinogen to Ang I by renin.

This study highlights the role of the cell surface in angiotensin II generation and opens new perspectives on the tissue renin-angiotensin system and on renin effects independent of angiotensin II.

ACE2 expression is significantly increased in liver injury in both humans and rat, and may modulate RAS activity in cirrhosis.

This study showed in a model of hepatic fibrosis the RAS activation. It also suggested that Ang-(I-7) played a protective role in hepatic fibrosis.

(Continued) 
Table I Continued

Sampaio et al 2007a

Sampaio et al 2007b

Santos et al 2008

Sarzani et al 2008

Tallant et al 2005

Tikellis et al 2003

Vincent et al 2003

Zisman et al 2003
This study demonstrated that, in human endothelial cells, Ang-(I-7) negatively modulates Ang II/Ang II type I receptor-activated c-Src and its downstream targets ERKI/2 and NAD $(P) H$ oxidase. They also show that SHP-2-c-Src interaction is enhanced by Ang-( I-7).

They demonstrated that Ang-(I-7), through Mas, stimulates eNOS activation and NO production via Aktdependent pathways.

The results from this study showed that Mas deficiency in FVB/N mice leads to dramatic changes in glucose and lipid metabolisms, inducing a metabolic syndrome-like state.

Cell proliferation was progressively stimulated by increasing Ang II concentrations and inhibited by atrial natriuretic pepetide in both visceral mature adipocytes and in vitro-differentiated preadipocytes. Co-incubation with increasing Ang II concentrations and valsartan indicated that Ang II effects were ATI-mediated.

The use of transfection of cultured myocytes with an antisense oligonucleotide to the mas receptor blocked in this model the ANG-(I-7)-mediated inhibition of serum-stimulated MAPK activation, whereas a sense oligonucleotide was ineffective. These results suggested that ANG-(I-7) reduced the growth of cardiomyocytes through activation of the mas receptor.

This study showed by immunostaining that both ACE2 and ACE protein were localized predominantly to renal tubules. In the diabetic kidney, there was reduced ACE2 protein expression that was prevented by ACE inhibitor therapy.

This study concludes that insulin specifically recruits flow to the microvasculture in skeletal muscle via a nitric oxidedependent pathway and that this may be important to insulin's overall action to regulate glucose disposal.

This study showed that Ang-(I-7)-forming activity from both Ang I and Ang II was increased in failing human heart ventricles but it was mediated by at least two different angiotensinases. The first, which demonstrated substrate preference for Ang I, was neutral endopeptidase-like.The second was ACE2, as demonstrated by Western blotting and inhibition of activity with $\mathrm{Cl} 6$.
In addition, the renal RAS is clearly activated in DM, with increased tissue Ang II (Giacchetti et al 2005) that leads to the development of diabetic nephropathy, a major cause of end-stage renal disease. Blockade of the RAS could thus reduce tissue Ang II levels, with beneficial effects on cardiovascular and renal function.

The so-called metabolic syndrome, now regarded as a global epidemic, includes obesity, insulin resistance, dyslipidemia, and hypertension, often with hypertriglyceridemia and reduced high-density lipoprotein, as well as hyperuricemia and increased C-reactive protein (Meigs 2003). These features are often associated with endothelial cell dysfunction with impaired control of vascular tone, increased adhesiveness of leukocytes, and increased formation of growth factors and cytokines. These processes have been implicated in the development of diabetes, hypertension, heart failure, atherosclerosis, and renal failure. In this context, RAS components, mostly Ang II, have a potential role in endothelial cell dysfunction, insulin resistance, inflammation, and proliferative effects (Watanabe et al 2005).

\section{Interactions between RAS, endothelium, and insulin signaling pathways}

The endothelium is a dynamic autocrine and paracrine organ that regulates vascular tonus and the interaction of the vascular wall with circulating substances and plasma cells (Cardillo and Panza 1998). It produces vasodilator and vasoconstrictor substances that are in balance under normal conditions. The health of the vascular net depends though on the normal operation of the endothelium. The endothelial dysfunction has been considered an imbalance in which the vasoconstrictor effects overcome the vasodilator ones in the vascular tonus (Jansson 2007; Pechánová et al 2007). This imbalance leads to a decrease of NO activity, which implies in a damage of the vascular protection (Pechánová et al 2007). The endothelium generally acts as a preventing barrier to the exocytose of macrophages and of low-density lipoproteins (LDL) to the subendothelium, and, thus protects against the atherosclerosis process (Romeo et al 2007).

The RAS can influence the vascular function by several ways, and studies have shown $\mathrm{AT}_{1}$ and $\mathrm{AT}_{2}$ receptors in the endothelium cells (Jacques et al 2003), besides evidence of Mas receptors, the Ang-(1-7) receptor (Sampaio et al 2007a, 2007b). Ang II generally exhibits a vasoconstrictor effect on the endothelium while Ang-(1-7) is preferentially a vasodilator peptide (Sampaio et al 2007b). Thus, the balance of these angiotensins' effects is probably involved in the maintenance of endothelium integrity. It is well established that Ang II produces endothelial dysfunction through different pathways, such as increasing the oxidative stress (Agarwal 2003) and 
Table 2 Summary of recent clinical research on renin-angiotensin system

\section{Author}

Bojestig et al 2000

Brenner et al 200I for the RENAAL Study

Dahlof et al 2002

Gross et al 2007

Gumprecht et al 2000

HOPE 2000

Lieb et al 2006

Lewis et al 200 I

Lindholm et al 2002

Matayoshi et al 2007

Merrill et al 2002

Mukai et al 2002

Nogueira et al 2007

Parving et al 200I

Simões e Silva et al 2006b

Simões e Silva et al 2004

Wijpkema et al 2006

Winkelmann et al 1999

\section{Results/Interpretations}

PRA and Ang II concentrations were significantly lower in diabetic patients than in the controls. The levels of atrial natriuretic peptide, on the other hand, were higher in patients than in controls. PRA correlated negatively to the mean value of $\mathrm{HbA}(\mathrm{Ic})$ during the previous five years.

Losartan reduced the incidence of a doubling of the serum creatinine concentration (risk reduction, $25 \% ; P=0.006$ ) and end-stage renal disease (risk reduction, $28 \% ; P=0.002$ ) but had no effect on the rate of death. Losartan conferred significant renal benefits in patients with type 2 diabetes and nephropathy.

Losartan prevents more cardiovascular morbidity and death than atenolol for a similar reduction in blood pressure and is better tolerated. Losartan seems to confer benefits beyond reduction in blood pressure, and new-onset diabetes was less frequent with losartan.

The survey of specific functional polymorphisms of the RAS, namely the angiotensin-I-converting enzyme (ACE) D/I, the angiotensinogen (AGT) TI74M and M235T, and A I I66C of the angiotensin-II receptor I (AGTRI), revealed that the incidence recurrent in-stent restenosis in a high-risk cohort was not associated with any of the polymorphisms examined in this study.

The results of this study suggest that ACE gene insertion/deletion and angiotensinogen M235T polymorphisms contribute to the increased risk for the development of chronic renal failure,

Ramipril was beneficial for cardiovascular events and overt nephropathy in people with diabetes. The cardiovascular benefit was shown to be greater than that attributable to the decrease in blood pressure.

This study provides evidence that genetic variants in the ACE2 gene may be associated with left ventricular mass, septal wall thickness, and left ventricular hypertrophy in hemizygous men.

The angiotensin-Il-receptor blocker irbesartan was effective in protecting against the progression of nephropathy due to type 2 diabetes. This protection was independent of the reduction in blood pressure it causes.

Losartan was more effective than atenolol in reducing cardiovascular morbidity and mortality as well as mortality from all causes in patients with hypertension, diabetes, and left ventricular hypertrophy. Losartan seems to have benefits beyond blood pressure reduction.

This study shows that the systemic RAS may modulate insulin sensitivity in essential hypertensive patients.

This study demonstrates, for the first time, increased plasma Ang-( I-7) in normal pregnant subjects compared with nonpregnant subjects and decreased Ang-(I-7) in preeclamptic subjects compared with normal pregnant subjects.

The results of this study demonstrate that long-term inhibition of the renin-angiotensin system ameliorates endothelial dysfunction associated with aging through the inhibition of the synthesis of COX-2-derived vasoconstricting factors and superoxide anions.

This study suggests that reduced levels of the vasodilator Ang-(I-7) could be implicated in the endothelial dysfunction seen in gestational diabetic women during and after pregnancy.

This study showed that Irbesartan is renoprotective independently of its blood-pressure-lowering effect in patients with type 2 diabetes and microalbuminuria

This study showed different circulating RAS profiles between hypertensive and in normotensive chronic renal failure subjects. Marked changes in plasma Ang-(I-7) were associated with the presence of hypertension and progression of kidney dysfunction.

This study showed different RAS profiles in childhood hypertension and suggested a blood pressure-independent change of Ang-(I-7) in essential hypertension.

In this study, the authors could establish a role for the ATIR II66A/C polymorphism in restenosis after percutaneous coronary intervention. However, significant gene - gene interaction was suggested for the ACE gene and the HO-I promotor, meriting further investigation in restenosis.

The significant relations observed in this study between the AGT M235T variant, its protein product, and the cardiovascular disease phenotypes provide evidence for a possible role of elevated circulating angiotensinogen in the pathogenesis of coronary artery disease.

(Continued) 
Table 2 Continued

\begin{tabular}{|c|c|}
\hline Yang et al 2007 & $\begin{array}{l}\text { The results of this study indicate that common genetic variants in the ACE2 gene might impact on } \\
\text { myocardial infarction in females, and may possibly interact with alcohol consumption to affect the } \\
\text { risk of coronary heart disease and myocardial infarction in Chinese males. }\end{array}$ \\
\hline Yusuf et al 200I & $\begin{array}{l}\text { This study demonstrated that ramipril is associated with lower rates of new diagnosis of diabetes } \\
\text { in high-risk individuals. }\end{array}$ \\
\hline Zhong et al 2006 & $\begin{array}{l}\text { This study concluded that the ACE } 2 \mathrm{~A} / \mathrm{G} \text { polymorphism is associated with hypertension in patients } \\
\text { with metabolic syndrome. }\end{array}$ \\
\hline Zisman et al 2003 & $\begin{array}{l}\text { This study showed that Ang-(I-7)-forming activity from both Ang I and Ang II was increased in } \\
\text { failing human heart ventricles but it was mediated by at least two different angiotensinases. The } \\
\text { first, which demonstrated substrate preference for Ang I, was neutral endopeptidase-like. The } \\
\text { second was ACE2, as demonstrated by Western blotting and inhibition of activity with CI6. }\end{array}$ \\
\hline
\end{tabular}

exerting proliferative (Clark et al 2008) and prothrombotic activities (Spillert et al 1994; Watanabe et al 2005). Ang II also stimulates the production of superoxide radicals, TGF- $\beta$, endothelin, and plasminogen activator inhibitor (PAI-1), which ultimately interferes in NO action (Rodrigues et al 2007). Thus, there is enough evidence that Ang II accumulation damages the endothelium and leads to atherosclerosis (Watanabe et al 2005; Cippolone et al 2006). However, other mediators are also responsible for endothelial function regulation (Savoia and Schiffrin 2007). In this regard, the vasoconstriction actions produced by Ang II and endothelin are probably opposed by the release of NO, prostaglandins, bradykinin as well as by Ang-(1-7). Furthermore, Ang-(1-7) promotes the release of $\mathrm{NO}$ and prostaglandins (Brosnihan et al 1996; Pörsti et al 1994) and potentiates bradykinin effects in different experimental models (Paula et al 1995;

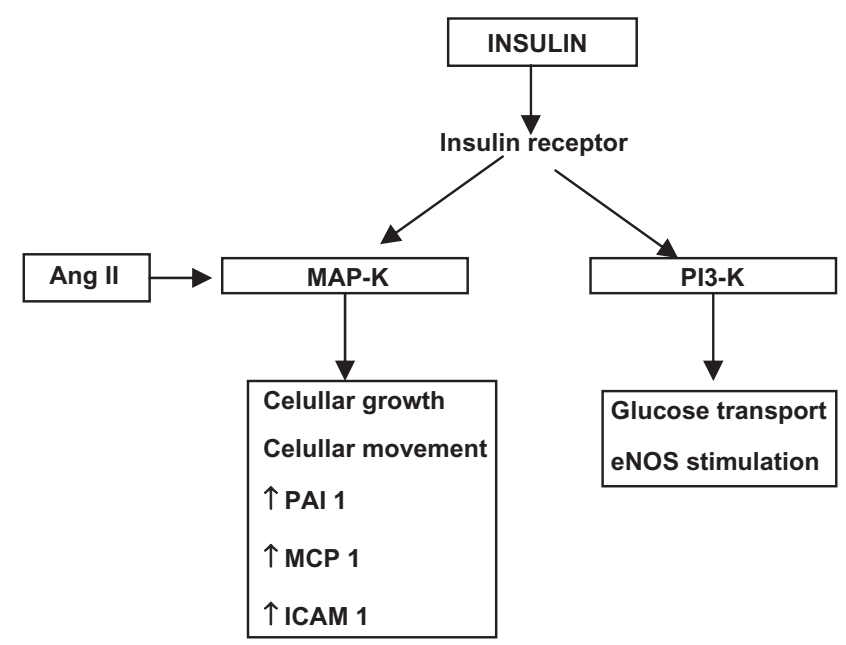

Figure 2 Interactions between angiotensin II and insulin receptor in vascular smooth muscle cells.

Abbreviations: Ang II, angiotensin II; MAPK, mitogen-activated protein kinase; PAI I, plasminogen activator inhibitor-I; MCP I, monocyte chemoattractant protein I; ICAM I, intracellular cell adhesion molecule-I; PI3K, inositol 3-phosphatidil kinase; eNOS, endothelial nitric oxide synthase.
Brosnihan et al 1996; Maia et al 2004). In addition, Ang (1-7) also inhibits the growth of VSMC (Freeman et al 1996), platelet aggregation and thrombosis (Kucharewicz et al 2002; Fraga-Silva et al 2008), inflammation, fibrosis (Pereira et al 2007), and oxidative stress (Benter et al 2008), which in turn might lead to endothelial function restoration.

Indeed, Ang-(1-7) can antagonize Ang II effects not only by the stimulation of other vasodilators but also through $\mathrm{AT}_{1}$ receptor inhibition. In this regard, Kostenis and colleagues (2005) reported that Mas receptor seems to act as a physiological antagonist of $\mathrm{AT}_{1}$ receptor and by so counteracts many Ang II actions (Figure 1).

Alterations in the synthesis and degradation of endothelial factors have recently been described as a contributor to the beginning or maintenance of a series of complications, including changes in vascular reactivity, blood flow, and tissue perfusion, which are all present in diabetes, renal diseases, heart failure, and hypertension (Kang et al 2002; Simões e Silva et al 2006c; Nakagawa et al 2007). Recently, studies have shown the presence of reduced levels of Ang-(1-7) in pregnancy complicated by pre-eclampsia (Merril et al 2002) and gestational diabetes (Nogueira et al 2007), corroborating to the hypothesis that changes in circulating levels of Ang-(17) can be a marker of a new onset endothelial dysfunction.

Clinical and experimental evidence show that ACE inhibitors and $\mathrm{AT}_{1}$ receptor blockers clearly improve endothelial dysfunction. Many mechanisms might take part in this effect and one of them is the increase of bradykinin levels with ACE inhibitors (Weir 2007). Considering that the treatment with RAS blockers (ACE inhibitors and $\mathrm{AT}_{1}$ receptor blockers) also increases Ang-(1-7) levels (Campbell 2003; Simões e Silva et al 2006b), our group and other investigators have speculated that the beneficial action of RAS blockade could be, at least in part, due to Ang-(1-7) effects (Simões e Silva et al 2006a; Santos and Ferreira 2007; Chappell 2007). 
In regard to diabetes, ACE inhibitors have also been associated to a decrease in the incidence of type 2 diabetes in hypertensive patients (Yusuf et al 2001; Vijayaraghavan and Deedwania 2005; Schmieder et al 2007), besides their wide spread utilization to prevent renal and cardiovascular diabetes complications (Weir 2007). Recent studies have shown an interaction between RAS and the insulin signaling pathways through $\mathrm{AT}_{1}$ receptors (Velloso et al 2006), and the utilization of $\mathrm{AT}_{1}$ receptor blockers have shown similar protective effects on renal and cardiovascular diabetes complications (Brenner et al 2001; Lindholm et al 2002). While Ang II may contribute to endothelial dysfunction and chronic diabetes complications, especially in the presence of insulin resistance (Hsueh and Quiñones 2003), treatment with $\mathrm{ACE}$ inhibitors or $\mathrm{AT}_{1}$ receptor blockers has shown to be protective in diabetes (Brenner et al 2001; Lindholm et al 2002). However, these studies have not addressed the possible role of Ang-(1-7) in this unclear mechanism by which $\mathrm{ACE}$ inhibitors or $\mathrm{AT}_{1}$ receptor blockers prevent diabetes complications and novel diabetes onset.

\section{Interactions between endothelial factors and insulin signaling}

Several studies in humans and animals have shown that insulin stimulated NO from the vascular endothelium represents an important physiologic role in the increase of the capillary recruitment and of the total blood flow to the skeletal muscle (Velloso et al 2006). The blunted endothelium NO-release has also been implicated in the reduction of capillary recruitment and of total blood flow, leading to a state of low glucose availability that characterizes insulin resistance (Hsueh and Quiñones 2003; Vincent et al 2003).

Besides its NO-dependent effects in the vascular endothelium, insulin also interferes with hemodynamic homeostasis in insulin resistant states (Yki-Jarvinen 2003). In these conditions, insulin can act through MAP-K pathway, promoting cellular growth and other pro-inflammatory and pro-thrombotic actions (Velloso et al 2006). In obese individuals, it has been speculated a possible shift from PI3-K pathway, the molecular via for insulin signal transduction into action, to the MAP-K pathway, offering a molecular explanation by which hyperinsulinemia of these individuals might play a pro-atherogenic role (Hsueh and Quiñones 2003). There is also a possible interaction between insulin and local RAS at this level, since Ang II through $\mathrm{AT}_{1}$ receptors may stimulate the MAP-K pathway and, by doing so, promotes cellular proliferation, inflammation and thrombosis (Velloso et al 2006), while the activation of $\mathrm{AT}_{2}$ receptors could inhibit this same via, meanwhile activating PI3-K (Bedecs et al 1997) (Figure 3). Although a possible antiproliferative action of Ang-(1-7) in this scenario is only speculative, experimental evidence with cardiomyocytes (Tallant et al 2005), pulmonary

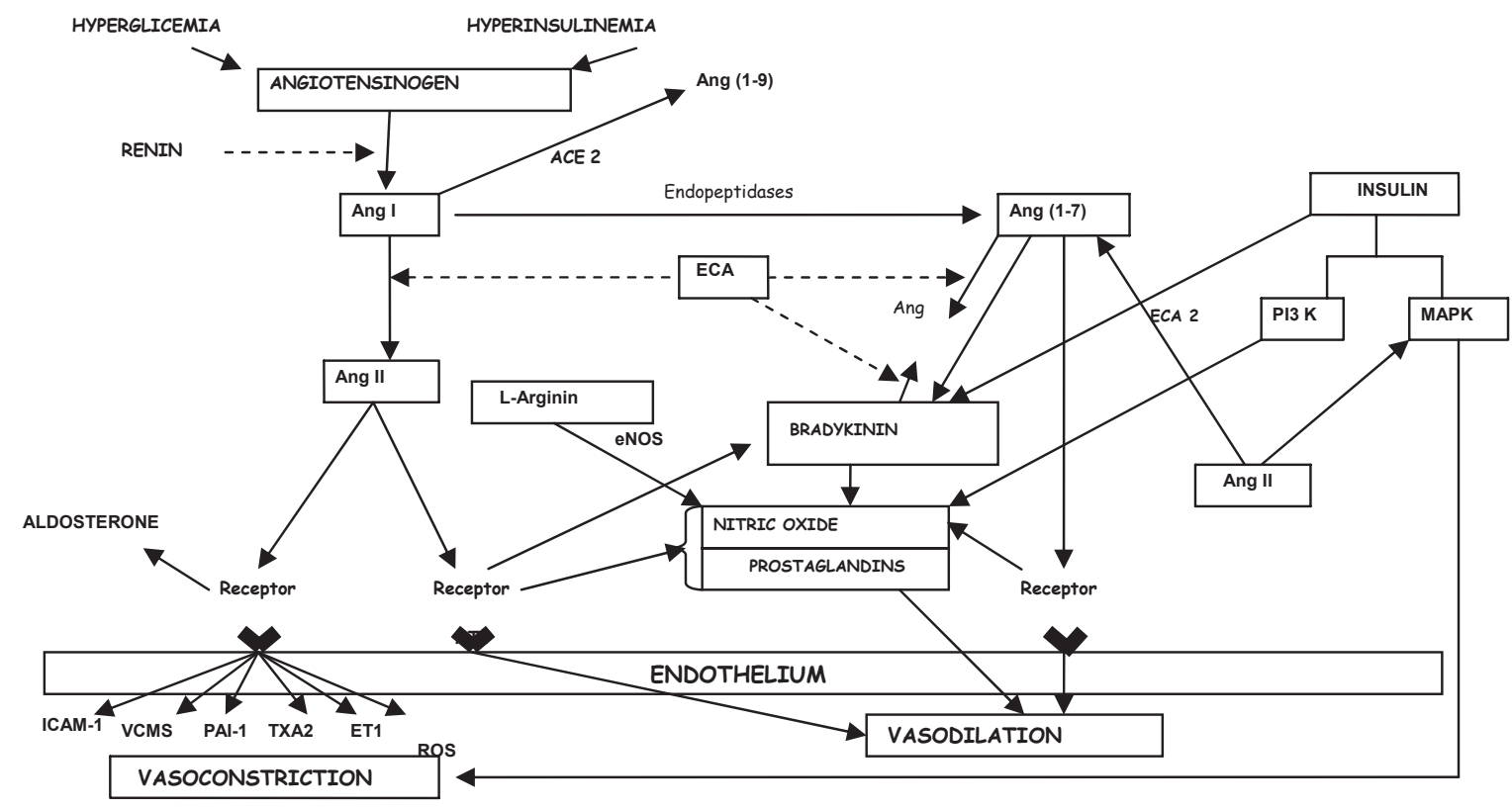

Figure 3 Interactions between renin-angiotensin system, kinin-kallikrein system, and insulin signaling transduction pathways.

Abbreviations: MAPK, mitogen-activated protein kinase; PI3K, inositol 3 phosphatidil kinase;Ang, Angiotensin;ACE, angiotensin-converting enzyme;ACE2, angiotensin-converting enzyme 2; $\mathrm{AT}_{1}, \mathrm{AT}_{2}$, angiotensinergic receptors types I and 2; Mas, Mas receptor of angiotensin-(I-7); NO, nitric oxide; eNOS, endothelial nitric oxide synthase; ROS, reactive oxygen species; ETI, endothelin I;TXA , thromboxane $\mathrm{A}_{2}$; PAI I, plasminogen activator inhibitor;VCMS, vascular smooth muscle cell; ICAMI, intracellular adhesion molecule I. 
tumor cells (Gallagher and Tallant 2004), and liver tissue (Pereira et al 2007; Herath et al 2007; Warner et al 2007) corroborates this possibility.

In addition, many studies have reported a connection between insulin resistance and RAS (Matayoshi et al 2007). It was shown that Ang II infusion induced insulin resistance (Richey et al 1999) and the blockade of the RAS improved insulin sensibility (Furuhashi et al 2004). In this regard, Santos and colleagues (2008) recently reported that, despite normal body weight, Mas-knockout mice in FVB/N background presented dyslipidemia, increased levels of insulin and leptin, and an approximately 50\% increase in abdominal fat mass. Mas deletion also led to glucose intolerance and reduced insulin sensitivity as well as a decrease in insulinstimulated glucose uptake by adipocytes and decreased GLUT4 in adipose tissue. These results indicated that Mas deficiency in FVB/N mice induces a metabolic syndromelike state. Further studies are obviously necessary to address the pathophysiological role of ACE2-Ang-(1-7)-Mas axis in human diabetes.

\section{RAS, diabetes, and the endothelium}

The cardiovascular morbidity and mortality related to diabetes, especially type 2 diabetes, are very high. Recently, cardiovascular risk has been reaching enormous proportions due to the obesity epidemic, metabolic syndrome, and type 2 diabetes. Large clinical trials have been conducted to address the increase in renal and cardiovascular complications in the diabetic patient. The results of United Kingdom Prospective Diabetes Study (UKPDS), Reduction of Endpoints in NonInsulin-Dependent Diabetes Mellitus with the Angiotensin II Antagonist Losartan (RENAAL), Irbesartan Diabetic Nephropathy Trial (IDNT) Patients with Type 2 Diabetes and Microalbuminuria Study (IRMA2), and Heart Outcomes Prevention Evaluation (HOPE and MICRO-HOPE) have shown that a well defined treatment of diabetic patients translated into renal and cardiovascular protection. Through these studies, it is now well established that prevention or reduction in proteinuria, blood pressure control, glycemic control, and particularly, the blockade of RAS are essential to prevent or delay the vascular diabetes complications. As already mentioned, RAS blockade has been shown not only a protective effect upon renal and cardiovascular complications of type 2 diabetes (Weir 2007), but also reduce novel type 2 diabetes onset in hypertensive patients as shown by HOPE (Lindholm et al 2002) and LIFE studies (Dahlof et al 2002).

Studies of RAS in diabetes have shown conflictive results regarding the activation of this system (Price et al 1999;
Bojestig et al 2000). For example, in diabetes nephropathy, studies have shown a suppression of plasma renin activity (Bjork 1990), while tissue renin are generally elevated (Anderson et al 1993). Therefore, although the evaluation of the circulating RAS components may be of importance, it may not give full information of intra renal RAS components.

Adipose tissue secretes a variety of hormones (known collectively as adipokines) that can modulate endothelial function. For example, TNF- $\alpha$ is a proinflammatory cytokine secreted by adipose cells that may cause insulin resistance and endothelial dysfunction (Rydén and Arner 2007). In addition, components of RAS, including AGT, renin, ACE, Ang II, and the $\mathrm{AT}_{1}$ and $\mathrm{AT}_{2}$ receptors are present in adipose tissue (Sarzani et al 2008). Ang II, through $\mathrm{AT}_{1}$ receptor, is able to modulate insulin actions, and this may be due to inhibition of cross-talk between Ang II signaling and insulin signaling in metabolic and vascular tissues (Caglayan et al 2005). In this regard, the addition of Ang II to endothelial cells activates MAP-K pathways, leading to increased serine phosphorylation of IRS-1, impaired PI3-K activity, and endothelial dysfunction, which is abolished by $\mathrm{AT}_{1}$ receptor blockers (Nakashima et al 2006). In addition to effects on insulin signaling, the activation of $\mathrm{AT}_{1}$ receptors stimulates the production of ROS via NADPH oxidase, increases expression of ICAM-1, and ET-1 release from the endothelium (Caglayan et al 2005). Therefore, there are multiple direct and indirect mechanisms by which RAS contribute to insulin resistance and endothelial dysfunction through the modulation of insulin signaling and other metabolic and vascular pathways (Caglayan et al 2005), supporting the therapeutic institution of RAS inhibition.

RAS blockade may be achieved through the inhibition of Ang II formation (with ACE or renin inhibitors), and through direct inhibition of $\mathrm{AT}_{1}$ receptors. In clinical scenario, ACE inhibitors and $\mathrm{AT}_{1}$ receptor blockers have been considered the most important ways of RAS blockade. The mechanism of action of ACE inhibitors results in accumulation of BK, whereas it does not occur with the $\mathrm{AT}_{1}$ receptor blockers. Other differences include the blockade of Ang II formation through $\mathrm{ACE}-$ independent pathways by $\mathrm{AT}_{1}$ receptor blockers (Li et al 2004), and a more prominent reduction of plasma blood flow by $\mathrm{AT}_{1}$ receptor blockers and renin inhibitors ( $\mathrm{Li}$ et al 2004). However, these agents have exhibited similar beneficial results in renal and cardiovascular diabetes complications (Yusuf et al 2001; Lindholm et al 2002).

In the HOPE study, diabetes incidence was lower in the group treated with ramipril when compared with placebo 
(Yusuf et al 2001). In the LIFE (Losartan Intervention For Endpoint Reduction in Hypertension) study, the use of losartan was associated with a reduction in the occurrence of new diabetes onset as compared with atenolol (Lindholm et al 2002). Although the precise mechanisms involved on the reduction of new type 2 diabetes diagnosis by RAS inhibition are not well established, the increase in insulin mediated glucose uptake (Jamerson et al 1996), the improvement of endothelial function (Mukai et al 2002), a decrease in inflammatory response (Mervaala et al 1999), an increase in BK and Ang-(1-7) levels (Maia et al 2004), and an effect in local system in the pancreatic islets (Lau et al 2004) have been suggested as some of the putative factors (Cooper et al 2006). To date, many studies have placed RAS inhibition as of great importance to prevent cardiovascular diabetes complications (HOPE, LIFE, and RENAAL Studies).

Concerning its preventive actions in type 2 diabetes, RAS inhibition has also been shown to improve insulin sensitivity, allowing a better insulin action or a reduction in insulin dosages in some patients (De Mattia et al 1996). Several studies, utilizing clamps for insulin sensibility evaluation, have confirmed these data in patients receiving ACE inhibitors or $\mathrm{AT}_{1}$ blockers (Yki-Jarvinen 1995).

RAS inhibition is of importance in the prognosis of renal diabetes complications of both type 1 and type 2 diabetes. Renal Ang II increases the capillary glomerular pressure, which ultimately translates into hyperfiltration and proteinuria (Navar et al 2000; Brewster and Perazella 2004). Deleterious Ang II effects have been demonstrated in experimental studies in which its infusion resulted in increase of intraglomerular pressure and protein excretion (Doria et al 1997). The resulting proteinuria associates to arterial hypertension and to the elevated risk of end stage renal disease, besides predicting cardiovascular complications of type 2 diabetes (Mogensen 1984; Deckert 1994). The beneficial effects of $\mathrm{ACE}$ inhibitors or $\mathrm{AT}_{1}$ receptor blockers upon diabetes nephropathy have been understood, at least in part, as a result of the attenuation of Ang II effects on blood pressure and glomerular hemodynamics (Carey and Siragy 2003b; Kalantrina and Okusa 2006). Besides these hemodynamic actions, Ang II also stimulates TGF $\beta 1$ and protein kinase $\mathrm{C}$ through $\mathrm{AT}_{1}$ receptors and thus increases extracellular matrix and vascular permeability (Kagami et al 1994; Wolf and Ziyadeh 1997; Carey and Siragy 2003b). These effects are quite similar to the results obtained with chronic hyperglycemia on the kidney, suggesting that the harmful renal hyperglycemic effects may be partially mediated by Ang II (Singh et al 1999). Of interest, hyperglycemia, the insulin resistance and the elevated free fatty acids may also stimulate renal Ang II generation, thus contributing to the pathogenesis of diabetes nephropathy (Carey and Siragy 2003b; Kalantrina and Okusa 2006). Furthermore, in the diabetic kidney, there was reduced ACE2 protein expression that was prevented by ACE inhibitor therapy (Tikellis et al 2003).

Many studies have also proven the role of ACE2 as a protective enzyme for cardiovascular diseases (see Table 2). As the ACE2 gene is on the $X$ chromosome, the studies correlating the ACE2 gene polymorphisms with cardiovascular and metabolic diseases have to take the gender into consideration meanwhile performing data analyses (Lieb et al 2006; Zhong et al 2006; Yang et al 2007). Although there is a lack of studies in this field, particularly in diabetes, a Chinese study has shown that patients with the metabolic syndrome exhibit an association of ACE2 gene A/G polymorphism and elevated blood pressure (Zhong et al 2006). Further studies should investigate the importance of these polymorphisms in diabetes, and also verify if the known polymorphisms in the RAS genes that have been studied in restenosis after percutaneous coronary intervention (Gross et al 2007; Wijpkema et al 2006) would also play a prominent role in diabetes and coronary disease.

Therefore, the identification of ACE2 in the kidney and cardiovascular system, its modulation in diabetes, and the recent description that this enzyme plays a biological role in the generation and degradation of various angiotensin peptides provide a rationale to further explore the role of ACE2-Ang-(1-7)-Mas axis in diabetic complications.

\section{Concluding remarks}

In conclusion, this review shows the physiology of the RAS, including the importance of novel mediators, receptors, and enzymatic pathways. It also shows how the current view of this system might impact diabetes and its complications, highlighting the importance of RAS inhibition in this disease treatment. Furthermore, we also provide recent evidence for putative role of ACE2-Ang-(1-7)-Mas axis in diabetes pathogenesis.

\section{Disclosure}

The authors report no conflict of interest.

\section{References}

Abdalla S, Lother H, Quitterer U. 2000. AT1-receptor heterodimers show enhanced G-protein activation and altered receptor sequestration. Nature, 407:94-8.

Agarwal R. 2003. Proinflammatory effects of oxidative stress in chronic kidney disease: role of additional angiotensin II blockade. Am J Physiol Renal Physiol, 284:F863-9. 
Albiston AL, McDowall SG, Matsacos D, et al. 2001. Evidence that the angiotensin IV (AT(4)) receptor is the enzyme insulin-regulated aminopeptidase. J Biol Chem, 276:48623-6.

Albiston AL, Peck GR, Yeatman HR, et al. 2007. Therapeutic targeting of insulin-regulated aminopeptidase: heads and tails? Pharmacol Ther, 116:417-27.

Albiston AL, Pederson ES, Burns P, et al. 2004. Attenuation of scopolamineinduced learning deficits by LVV-hemorphin-7 in rats in the passive avoidance and water maze paradigms. Behav Brain Res, 154:239-43.

Anderson S, Jung FF, Ingelfinger JR. 1993. Renal renin-angiotensin system in diabetes: functional immunohistochemical and molecular biological correlations. Am J Physiol, 265:F477-486.

Baker KM, Chernin MI, Schreiber T, et al. 2004. Evidence of a novel intracrine mechanism in angiotensin II-induced cardiac hypertrophy. Regul Pept, 120:5-13.

Bedecs K, Elbaz N, Sutrem M, et al. 1997. Angiotensin II type 2 receptors mediate inhibition of mitogen activated protein kinase cascade and functional activation of SHP-1 tyrosine phosphatase. Biochem J, 325:449-54

Benter IF, Yousif MH, Dhaunsi GS, et al. 2008. Angiotensin (1-7) prevents activation of NADPH oxidase and renal vascular dysfunction in diabetic hypertensive rats. Am J Nephrol, 28:25-33.

Bjork S. 1990. The renin-angiotensin system in diabetes mellitus: a physiological and therapeutic study. Scand J Urol Nephrol, 126:1-50.

Bloem LJ, Manatunga AK, Tewksbury DA, et al. 1995. The serum angiotensinogen concentration and variants of the angiotensinogen gene in white and black children. J Clin Invest, 95:948-53.

Bojestig M, Nystrom FH, Arnqvist HJ, et al. 2000. The renin-angiotensinaldosterone system is suppressed in adults with Type 1 diabetes. J Renin Angiotensin Aldosterone Syst, 1:353-6.

Braszko JJ, Walesiuk A, Wielgat P. 2006. Cognitive effects attributed to angiotensin II may result from its conversion to angiotensin IV. J Renin Angiotensin Aldosterone Syst, 7:168-74.

Braun-Menendez E, Fasciolo JC, Leloir LF, et al. 1940. The substance causing renal hypertension. J Physiol (Lond), 98:283-98.

Brenner BM, Cooper ME, de Zeeuw D, et al. for the RENAAL Study Investigators. 2001. Effects of losartan on renal and cardiovascular outcomes in patients with type 2 diabetes and nephropathy. $N$ Eng $J$ Med, 345:861-9.

Brewster UC, Perazella MA. 2004. The renin-angiotensin-aldosterone system and the kidney: effects on kidney disease. Am J Med, 116:263-72.

Brosnihan KB, Li P, Ferrario CM. 1996. Angiotensin-(1-7) dilates canine coronary arteries through kinins and nitric oxide. Hypertension, 27:523-8.

Brosnihan KB, Neves LA, Anton L, et al. 2004. Enhanced expression of Ang (1-7) during pregnancy. Braz J Med Biol Res, 37:1255-62.

Caglayan E, Blaschke F, Takata Y, et al. 2005. Metabolic syndrome interdependence of the cardiovascular and metabolic pathways. Curr Opin Pharmacol, 5:135-42.

Campagnole-Santos MJ, Diz DI, Santos RAS, et al. 1989. Cardiovascular effects of angiotensin-(1-7) injected into the dorsal medulla of rats. $\mathrm{Am}$ J Physiol, 257:H324-9.

Campbell DJ. 2003. The renin angiotensin and kallikrein kinin systems. Int J Biochem Cell Biol, 35:784-91.

Cardillo C, Panza JA. 1998. Impaired endotelial regulation of vascular tone in patients with systemic arterial hypertension. Vasc Med, 3:138-44.

Carey RM, Siragy HM. 2003a. Newly recognized components of the renin-angiotensin system: potential roles in cardiovascular and renal regulation. Endocr Rev, 24(3):261-71.

Carey RM, Siragy HM. 2003b. The intrarenal renin-angiotensin system and diabetic nephropathy. Trends Endocrinol Metab, 14(6):274-81.

Cesari M, Rossi GP, Pessina AC. 2002. Biological properties of the angiotensin peptides other than angiotensin II: implications for hypertension and cardiovascular diseases. J Hypertens, 20:793-9.

Chappell MC, Modrall JG, Diz DI, et al. 2004. Novel aspects of the renal Renin-Angiotensin System: Angiotensin-(1-7), ACE2 and blood pressure regulation. Contrib Nephrol, 143:77-89.
Chappell MC. 2007. Emerging evidence for a functional angiotensinconverting enzyme 2-angiotensin-(1-7)-Mas receptor axis: More than regulation of blood pressure? Hypertension, 50:596-9.

Chay SR, Fernando R, Peck G, et al. 2004. The angiotensin IV/AT4 receptor. Cell Mol Life Sci, 61:2728-37.

Chen S, Patel JM, Block ER. 2000. Angiotensin IV-mediated pulmonary artery vasorelaxation is due to endothelial intracellular calcium release. Am J Physiol, 279:L849-56.

Cipollone F, Fazia ML, Mezzeti A. 2006. Role of angiotensin II receptor blockers in atherosclerotic plaque stability. Expert Opin Pharmacother, $7: 277-85$.

Clark MA, Guillaume G, Pierre-Louis HC. 2008. Angiotensin II induces proliferation of cultured rat astrocytes through c-Jun N-terminal kinase. Brain Res Bull, 75:101-6.

Cooper ME, Tikellis C, Thomas MC. 2006. Preventing diabetes in patients with hypertension: one more reason to block the renin-angiotensin system. J Hypertens Suppl, 24:S57-63.

Dahlof B, Devereux RB, Kjeldsen SE, et al. 2002. Cardiovascular morbidity and mortality in the Losartan Intervention for Endpoint Reduction in Hypertension Study (LIFE): a randomized trial against atenolol. Lancet, 359:995-1003.

Danser AH. 2003. Local renin-angiotensin systems: the unanswered questions. Int J Biochem Cell Biol, 35:759-68.

De Gasparo M, Catt KJ, Inagami T, et al. 2000. International union of pharmacology. XXIII. The angiotensin II receptors. Pharmacol Rev, 52:415-72.

De Mattia G, Ferri C, Laurenti O. 1996. Circulating cathecolamines and metabolic effects of captopril in NIDDM patients. Diabetes Care, 19:226-30.

Deckert T. 1994. Nephropathy and coronary death: the fatal twins in diabetes mellitus. Nephrol Dial Transplant, 9:1069-71.

Deddish PA, Marcic B, Jackman HL, et al. 1998. N-domain-specific substrate and $\mathrm{C}$-domain inhibitors of angiotensin-converting enzyme: angiotensin-(1-7) and keto-ACE. Hypertension, 31:912-17.

Donoghue M, Hsieh F, Baronas E, et al. 2000. A novel angiotensin-converting enzyme-related carboxypeptidase (ACE2) converts angiotensin I to angiotensin 1-9. Circ Res, 87:E1-9.

Doria A, Onuma T, Warram JH, et al. 1997. Synergistic effect of angiotensin II type 1 receptor genotype and poor glycaemic control on risk of nephropathy in IDDM. Diabetologia, 40:1293-99.

Fei DT, Coghlan JP, Fernley RT, et al. 1980. Peripheral production of angiotensin II and III in sheep. Circ Res, 46:I135-7.

Ferrario C, Abdelhamed AI, Moore M. 2004. Angiotensin II antagonists in hypertension, heart failure, and diabetic nephropathy: focus on losartan. Curr Med Res Opin, 20:279-93.

Ferrario CM, Jessup J, Gallagher PE, et al. 2005. Effects of renin-angiotensin system blockade on renal angiotensin-(1-7) forming enzymes and receptors. Kidney Int, 68:2189-96.

Ferrario CM, Martell N, Yunis C, et al. 1998. Characterization of angiotensin-(1-7) in the urine of normal and essential hypertensive subjects. Am J Hypertens, 11:137-46.

Folli F, Saad MJ, Velloso L, et al. 1999. Crosstalk between insulin and angiotensin II signalling systems. Exp Clin Endocrinol Diabetes, 107:133-9.

Fraga-Silva RA, Pinheiro SV, Gonçalves AC, et al. 2008. The Antithrombotic Effect of Angiotensin-(1-7) Involves Mas-Mediated NO Release from Platelets. Mol Med, 14:28-35.

Freeman EJ, Chisolm GM, Ferrario CM, et al. 1996. Angiotensin (1-7) inhibits vascular smooth muscle cell growth. Hypertension, 28:104-8.

Frossard M, Joukhadar C, Steffen G, et al. 2000. Paracrine effects of angiotensin-converting-enzyme-and angiotensin-II-receptor-inhibition on transcapillary glucose transport in humans. Life Sci, 66:147-54.

Furuhashi M, Ura N, Takizawa H, et al. 2004. Blockade of the reninangiotensin system decreases adipocyte size with improvement in insulin sensitivity. J Hypertens, 22:1977-82.

Gallagher PE, Tallant EA. 2004. Inhibition of human lung cancer cell growth by angiotensin-(1-7). Carcinogenesis, 25:2045-52. 
Ganten D, Marquez-Julio A, Granger P, et al. 1971. Renin in dog brain. Am J Physiol, 221:1733-7.

Giacchetti G, Sechi LA, Rilli S, et al. 2005. The renin-angiotensinaldosterone system, glucose metabolism and diabetes. Trends Endocrinol Metab, 16:120-6.

Glossmann H, Baukal A, Catt KJ. 1974. Angiotensin II receptors in bovine adrenal cortex. Modification of angiotensin II binding by guanyl nucleotides. J Biol Chem, 249:664-6.

Gross CM, Perrot A, Geier C, et al. 2007. Recurrent in-stent restenosis is not associated with the angiotensin-converting enzyme $\mathrm{D} / \mathrm{I}$, angiotensinogen Thr174Met and Met235Thr, and the angiotensin-II receptor $1 \mathrm{~A} 1166 \mathrm{C}$ polymorphism. J Invasive Cardiol, 19:261-4.

Gumprecht J, Zychma MJ, Grzeszczak W, et al. 2000. End-stage renal disease study group. Angiotensin I-converting enzyme gene insertion deletion and angiotensinogen M235T polymorphisms: risk of chronic renal failure. Kidney Int, 58:513-19.

Hall JE, Brands MW, Henegar JR. 1999. Angiotensin II and long-term arterial pressure regulation: the overriding dominance of the kidney. $J$ Am Soc Nephrol, 10:S258-65.

Hall JE. 1991. The renin-angiotensin system: renal actions and blood pressure regulation.Compr Ther, 17:8-17.

Handa RK. 1999. Angiotensin-(1-7) can interact with the rat proximal tubule AT(4) receptor system. Am J Physiol, 277:F75-F83.

[HOPE] Heart Outcomes Prevention Evaluation Study Investigators. 2000 Effects of ramipril on cardiovascular and microvascular outcomes in people with diabetes mellitus: results of the HOPE study and MICRO-HOPE substudy. Lancet, 355:253-9.

Herath CB, Warner FJ, Lubel JS, et al. 2007. Upregulation of hepatic angiotensin-converting enzyme 2 (ACE2) and Angiotensin-(1-7) levels in experimental billiary fibrosis. J Hepatol, 47:387-95.

Hsueh WA, Quiñones MJ. 2003. Role of endothelial dysfunction in insulin resistance. Am J Card, 92:10J-17J.

Hunyady L, Catt KJ. 2006. Pleiotropic AT1 receptor signaling pathways mediating physiological and pathogenic actions of angiotensin II. Mol Endocrinol, 20:953-70.

Ichikawa I, Harris RC. 1991. Angiotensin actions in the kidney. Renewed insight into the old hormone. Kidney Int, 40:583-96.

Jackman HL, Massad MG, Sekosan M, et al. 2002. Angiotensin 1-9 and 1-7 release in human heart: role of cathepsin A. Hypertension, 39:976-81.

Jacques D, Abdel Malak NA, Sader S, et al. 2003. Angiotensin II and its receptors in human endocardial endothelial cells : role in modulating intracellular calcium. Can J Physiol Pharmacol, 81:259-66.

Jamerson KA, Nesbitt SD, Amerena JV, et al. 1996. Angiotensin mediates forearm glucose uptake by hemodynamic rather than direct effects. Hypertension, 27:854-8.

Jandeleit-Dahm KA, Tikellis C, Reid CM, et al. 2005. Why blockade of the renin-angiotensin system reduces the incidence of new-onset diabetes. J Hypertens, 23:463-73.

Jankowski V, Vanholder R, van der Giet M, et al. 2007. Mass-spectrometric identification of a novel angiotensin peptide in human plasma. Arterioscler Thromb Vasc Biol, 27:297-302.

Jansson PA. 2007. Endothelial dysfunction in insulin resistance and type 2 diabetes. J Intern Med, 262:173-83.

Kagami S, Border WA, Miller DE, et al. 1994. Angiotensin II stimulates extracellular matrix protein synthesis through induction of transforming growth factor-beta expression in the rat glomerular mesangial cells. $J$ Clin Invest, 93:2431-7.

Kalantarinia K, Okusa MD. 2006. The renin-angiotensin system and its blockade in diabetic renal and cardiovascular disease. Curr Diab Rep, 6:8-16.

Kambayashi Y, Bardhan S, Takahashi K, et al. 1993. Molecular cloning of a novel angiotensin II receptor isoform involved in phosphotyrosine phosphatase inhibition. J Biol Chem, 268:24543-6.

Kang D-H, Kanellis J, Hugo C, et al. 2002. Role of the microvascular endothelium in progressive renal disease. $J$ Am Soc Nephrol, 13:806-16.
Karwowska-Polecka W, Kulakowska A, Wisniewski K, et al. 1997. Losartan influences behavioral effects of angiotensin II (3-7) in rats. Pharmacol Res, 36:275-83.

Kohlstedt K, Brandes RP, Muller-Esterl W, et al. 2004. Angiotensinconverting enzyme is involved in outside-in signaling in endothelial cells. Circ Res, 94:60-7.

Kostenis E, Milligan G, Christopoulos A, et al. 2005. G-protein-coupled receptor Mas is a physiological antagonist of the angiotensin II type 1 receptor. Circulation, 111:1806-13.

Kucharewicz I, Pawlak R, Matys T, et al. 2002. Antithrombotic effect of captopril and losartan is mediated by angiotensin-(1-7). Hypertension, 40:774-9.

Lau T, Carlsson PO, Leung PS. 2004. Evidence for a local angiotensingenerating system and dose-dependent inhibition of glucose-stimulated insulin release by angiotensin II in isolated pancreatic islets. Diabetologia, 47:240-8.

Lavoie JL, Sigmund CD. 2003. Minireview: overview of the reninangiotensin system-an endocrine and paracrine system. Endocrinology, 144:2179-83.

Lewis EJ, Hunsicker LG, Clark WR, et al; for The Collaborative Study Group. 2001. Renoprotective effect of the angiotensin receptor antagonist irbersartan in patients with nephropathy due to type 2 diabetes. N Engl J Med, 345:851-60.

Li M, Liu K, Michalicek J, et al. 2004. Involvement of chymase-mediated angiotensin II generation in blood pressure regulation. J Clin Invest, $114: 112-20$

Li XC, Campbell DJ, Ohishi M, et al. 2006. AT1 receptor-activated signaling mediates angiotensin IV-induced renal cortical vasoconstriction in rats. Am J Physiol, 290:F1024-33.

Lieb W, Graf J, Gotz A, et al. 2006. Association of angiotensin-converting enzyme 2 (ACE2) gene polymorphisms with parameters of left ventricular hypertrophy in men. Results of the MONICA Augsburg echocardiographic substudy. J Mol Med, 84:88-96.

Lindholm LH, Ibsen H, Dahlof B. 2002. Cardiovascular morbidity and mortality in patients with diabetes in the Losartan Intervention For Endpoint reduction in hypertension study (LIFE). A randomized trial against atenolol. Lancet, 359:1004-10.

Lupi R, Del Guerra S, Bugliani M, et al. 2006. The direct effects of the angiotensin-converting enzyme inhibitors, zofenoprilat and enalaprilat, on isolated human pancreatic islets. Eur J Endocrinol, 154:355-61.

Luque M, Martin P, Martell N, et al. 1996. Effects of captopril related to increased levels of prostacyclin and angiotensin-(1-7) in essential hypertension. J Hypertens, 14:799-805.

Maia LG, Ramos MC, Fernandes L, et al. 2004. Angiotensin - (1-7) antagonist A-779 attenuates the potentiation of bradykinin by captopril in rats. J Cardiovasc Pharmacol, 43:685-91.

Matayoshi T, Kamide K, Takiuchi S, et al. 2007. Relationship between insulin resistance and the renin-angiotensin system: analysis for patients with essential and renovascular hypertension. Clin Exp Hypertens, 29:479-87.

Meigs JB. 2003. The metabolic syndrome. Br Med J, 327:61-2.

Merril DC, Karoly M, Chen K, et al. 2002. Angiotensin-(1-7) in normal and pre-elamptic pregnancy. Endocrine, 18:239-45.

Mervaala EM, Muller DN, Park JK, et al. 1999. Monocyte infiltration and adhesion molecules in a rat model of high human renin hypertension. Hypertension, 33:389-95.

Miyazaki M, Takai S. 2006. Tissue angiotensin II generating system by angiotensin-converting enzyme and chymase. J Pharmacol Sci, 100:391-7.

Mogensen CE. 1984. Microalbuminuria predicts clinical proteinuria and early mortality in maturity onset diabetes. $N$ Eng $J$ Med, 310:356-60.

Mogielnicki A, Kramkowski K, Chabielska E, et al. 2003. Angiotensin 1-9 influences hemodynamics and hemostatics parameters in rats. Pol J Pharmacol, 55:503-4.

Mukai Y, Shimokawa H, Higashi M, et al. 2002. Inhibition of reninangiotensin system ameliorates endothelial dysfunction associated with aging rats. Arterioscler Thromb Vasc Biol, 22:1445-50. 
Mukoyama M, Nakajima M, Horiuchi M, et al. 1993. Expression cloning of type 2 angiotensin II receptor reveals a unique class of seventransmembrane receptors. $J$ Biol Chem, 268:24539-42.

Muller M, Fasching P, Schmid R, et al. 1997. Inhibition of paracrine angiotensin-converting enzyme in vivo: effects on interstitial glucose and lactate concentrations in human skeletal muscle. Eur J Clin Invest, $27: 825-30$.

Murphy TJ, Alexander RW, Griendling KK, et al. 1991. Isolation of a cDNA encoding the vascular type-1 angiotensin II receptor. Nature, 351:233-6.

Naber CK, Siffert W. 2004. Genetics of human arterial hypertension. Minerva Med, 95:347-56.

Nagata S, Kato J, Sasaki K, et al. 2006. Isolation and identification of proangiotensin-12, a possible component of the renin-angiotensin system. Biochem Biophys Res Comm, 350:1026-31.

Nakagawa T, Segal M, Croker B, et al. 2007. A breakthrough in diabetic nephropathy: the role of endothelial dysfunction. Nephrol Dial Transplant, 22:2775-7.

Nakashima H, Suzuki H, Ohtsu H, et al. 2006. Angiotensin II regulates vascular and endothelial dysfunction: recent topics of Angiotensin II type-1 receptor signaling in the vasculature. Curr Vasc Pharmacol, 4:67-78.

Navar LG, Harrison BL, Imig JD, et al. 2000. Renal responses to AT(1) receptor blockade. Am J Hypertens, 13:S45-54.

Navar LG, Nishiyama A. 2004. Why are angiotensin concentrations so high in the kidney? Curr Opin Nephrol Hypertens, 13:107-15.

Nguyen G, Delarue F, Burckle C, et al. 2002. Pivotal role of the renin/prorenin receptor in angiotensin II production and cellular responses to renin. J Clin Invest, 109:1417-27.

Nielsen AH, Schauser KH, Poulsen K. 2000. Current topic: the uteroplacental renin-angiotensin system. Placenta, 21:468-77.

Nogueira AI, Santos RAS, Simões e Silva AC, et al. 2007. The pregnancyinduced increase of plasma angiotensin-(1-7) is blunted in gestational diabetes. Regul Pep, 141:55-60.

Nouet S, Nahmias C. 2000. Signal transduction from the Angiotensin II AT2 receptor. Trends Endocrinol Metab, 11:1-6.

Orcaranza MP, Godoy I, Jalil JE, et al. 2006. Enalapril attenuates downregulation of Angiotensin-converting enzyme 2 in the late phase of ventricular dysfunction in myocardial infarcted rat. Hypertension, 48: 572-8.

Padia SH, Howell NL, Siragy HM, et al. 2006. Renal angiotensin type 2 receptors mediate natriuresis via angiotensin III in the angiotensin II type 1 receptor-blocked rat. Hypertension, 47:537-44.

Padia SH, Kemp BA, Howell NL, et al. 2007. Intrarenal aminopeptidase N inhibition augments natriuretic responses to angiotensin III in angiotensin type 1 receptor-blocked rats. Hypertension, 49:625-30.

Paizis G, Tikellis C, Cooper ME, et al. 2005. Chronic liver injury in rat and man upregulates the novel enzyme angiotensin converting enzyme II. Gut, 54:1790-6.

Parving HH, Lehnert H, Brochner-Mortensen J, et al; for the Irbesartan in Patients with Type 2 Diabetes and Microalbuminuria Study Group. 2001. The effect of irbesartan on the development of diabetic nephropathy in patients with type 2 diabetes. $N$ Engl J Med, 345:870-8.

Patel JM, Martens JR, Li YD, et al. 1998. Angiotensin IV receptor-mediated activation of lung endothelial NOS is associated with vasorelaxation. Am J Physiol, 275:L1061-8.

Paul M, Mehr AP, Kreutz R. 2006. Physiology of local renin-angiotensin systems. Physiol Rev, 86:747-803.

Paula RD, Lima CV, Khosla MC, et al. 1995. Angiotensin -(1-7) potentiates the hypotensive effect of bradykinin in conscious rats. Hypertension, 26:1154-9.

Pechánová O, Simko F. 2007. The role of nitric oxide in the maintenance of vasoactive balance. Physiol Res, 56(Suppl 2):S7-16.

Pereira RM, Santos RAS, Teixeira MM, et al. 2007. The renin-angiotensin system in a rat model of hepatic fibrosis: Evidence for a protective role of angiotensin-(1-7). J Hepatol, 46:674-81.

Plovsing RR, Wamberg C, Sandgaard NC, et al. 2003. Effects of truncated angiotensins in humans after double blockade of the renin system. $\mathrm{Am}$ J Physiol, 285:R981-91.
Porsti I, Bara AT, Busse R, et al. 1994. Release of nitric oxide by angiotensin-(1-7) from porcine coronary endothelium: implications for a novel angiotensin receptor. Br J Pharmacol, 111:652-4.

Price DA, De'Oliveira JM, Fisher ND, et al. 1999. The state and responsiveness of the renin-angiotensin system in patients with type II diabetes mellitus. Am J Hypertens, 12:348-55.

Re RN. 2003. Intracellular renin and the nature of intracrine enzymes. Hypertension, 42:117-22.

Rice GI, Thomas DA, Grant PJ, et al. 2004. Evaluation of angiotensinconverting enzyme (ACE), its homologue ACE2 and neprilysin in angiotensin peptide metabolism. Biochem J, 383:45-51.

Richey JM, Ader M, Moore D, et al. 1999. Angiotensin II induces insulin resistance independent of changes in interstitial insulin. Am J Physiol, 277:920-6.

Rodriguez A, Fortuño A, Gómez-Ambrosi J, et al. 2007. The inhibitory effect of leptin on angiotensin II-induced vasoconstriction in vascular smoth muscle cells is mediated via a nitric oxide-dependent mechanism. Endocrinology, 148:324-31.

Romeo GR, Moulton KS, Kazlauskas A, et al. 2007. Attenuated expression of profilin-1 confers protection from atherosclerosis in the LDL receptor null mouse. Circ Res, 101:328-30.

Ruiz-Ortega M, Lorenzo O, Egido J. 2000. Angiotensin III increases MCP-1 and activates NF-kappaB and AP-1 in cultured mesangial and mononuclear cells. Kidney Int, 57:2285-98.

Rydén M, Arner P. 2007. Tumour necrosis factor-alpha in human adipose tissue - from signaling mechanisms to clinical implications. $J$ Intern Med, 262:431-8.

Sampaio WO, Henrique de Castro C, Santos RA, et al. 2007a. Angiotensin(1-7) counterregulates angiotensin II signaling in human endothelial cells. Hypertension, 50:1093-8.

Sampaio WO, Souza dos Santos RA, Faria-Silva R, et al. 2007b. Angiotensin(1-7) through receptor Mas mediates endothelial nitric oxide synthese activation via Akt-dependent pathways. Hypertension, 49:185-92.

Santos RAS, Brosnihan KB, Chappell MC, et al. 1988. Converting enzyme activity and angiotensin metabolism in the dog brainstem. Hypertension, 11:153-7.

Santos RAS, Ferreira AJ. 2005. Cardiovascular actions of Angiotensin-(1-7). Braz J Med Biol Res, 38:499-507.

Santos RAS, Ferreira AJ. 2007. Angiotensin-(1-7) and the renin-angiotensin system. Curr Opin Nephrol Hypertens, 16:122-8.

Santos RAS, Simões e Silva AC, Maric C, et al. 2003. Angiotensin-(1-7) is an endogenous ligand for the $\mathrm{G}$ protein-coupled receptor Mas. Proc Natl Acad Sci USA, 100: 8258-63.

Santos SH, Fernandes LR, Mario EG, et al. 2008. Mas deficiency in FVB/N mice produces marked changes in lipid and glycemic metabolism. Diabetes, 57:340-7.

Sarzani R, Marcucci P, Salvi P, et al. 2008. Angiotensin II stimulates and atrial natriuretic peptide inhibits human visceral adipocyte growth. Int J Obes, 32:259-67.

Sasaki K, Yamano Y, Bardhan S, et al. 1991. Cloning and expression of a complementary DNA encoding a bovine adrenal angiotensin II type-1 receptor. Nature, 351:230-3.

Savoia C, Schiffrin EL. 2007. Vascular inflammation in hypertension and diabetes: molecular mechanisms and therapeutic interventions. Clin Sci, 112:375-84.

Schiavone MT, Santos RAS, Brosnihan KB, et al. 1988. Release of vasopressin from the rat hypothalamo-neurohypophysial system by angiotensin-(1-7) heptapeptide. Proc Natl Acad Sci USA, 85:4095-8.

Schmieder RE, Hilgers KF, Schlaich PM, et al. 2007. Renin-angiotensin system and cardiovascular risk. Lancet, 369:1208-19.

Sernia C. 2001. A critical appraisal of the intrinsic pancreatic angiotensingenerating system. JOP, 2:50-5.

Shah DM. 2005. Role of the renin-angiotensin system in the pathogenesis of preeclampsia. Am J Physiol Renal Physiol, 288:F614-25.

Simões e Silva AC, Diniz JS, Pereira RM, et al. 2006b. Circulating renin angiotensin system in childhood chronic renal failure: Marked increase of angiotensin-(1-7) in end-stage renal disease. Pediatr Res, 60:734-9. 
Simões e Silva AC, Diniz JS, Regueira-Filho A, et al. 2004. The renin angiotensin system in childhood hypertension: Selective increase of angiotensin-(1-7) in essential hypertension. J Pediatr, 145:93-8.

Simões e Silva AC, Pinheiro SVB, Pereira RM, et al. 2006a. The therapeutic potential of Angiotensin-(1-7) as a novel Renin Angiotensin System mediator. Mini Rev Med Chem, 6:603-9.

Simões e Silva AC. 2006c. Pathophysiology of arterial hypertension: Insights from pediatric studies. Curr Pediatr Rev, 2:209-23.

Singh R, Alavi N, Singh AK, et al. 1999. Role of angiotensin II in glucose-induced inhibition of mesangial matrix degradation. Diabetes, 48:2066-73.

Skeggs LT Jr, Kahn JR, Shumway NP. 1956. The preparation and function of the hypertensin-converting enzyme. J Exp Med, 103:295-9.

Slinker BK, Wu Y, Brennan AJ, et al. 1999. Angiotensin IV has mixed effects on left ventricle systolic function and speeds relaxation. Cardiovasc Res, 42:660-9.

Spät A, Hunyady L. 2004. Control of aldosterone secretion: a model for convergence in cellular signaling pathways. Physiol Rev, 84:489-539.

Spillert CR, Sun S, Miller MA, et al. 1994. Hypertension-related coronary thrombosis: prothrombic role of angiotensin II. J Natl Med Assoc, 86:686-8.

Staessen JA, Li Y, Richart T. 2006. Oral renin inhibitors. Lancet, 368:1449-56.

Suzuki S, Doi Y, Aoi W, et al. 1984. Effect of angiotensin III on blood pressure, renin-angiotensin-aldosterone system in normal and hypertensive subjects. Jpn Heart J, 25:75-85.

Tallant EA, Ferrario CM, Gallagher PE. 2005. Angiotensin-(1-7) inhibits growth of cardiac myocytes through activation of the mas receptor. Am J Physiol, 289:H1560-6.

Tikellis C, Johnston CI, Forbes JM, et al. 2003. Characterization of renal angiotensin-converting enzyme 2 in diabetic nephropathy. Hypertension, 41:392-7.

Tipnis SR, Hooper NM, Hyde R, et al. 2000. A human homolog of angiotensin-converting enzyme. Cloning and functional expression as a captopril-insensitive carboxypeptidase. J Biol Chem, 275:33238-43.

Touyz RM, Schiffrin EL. 2000. Signal transduction mechanisms mediating the physiological and pathophysiological actions of angiotensin II in vascular smooth muscle cells. Pharmacol Rev, 52:639-72.

Velloso LA, Folli F, Perego L, et al. 2006. The multi-faceted cross-talk between the insulin and angiotensin II signaling systems. Diabetes Metab Res Rev, 22:98-107.

Vickers C, Hales P, Kaushik V, et al. 2002. Hydrolysis of biological peptides by human angiotensin-converting enzyme-related carboxypeptidase. J Biol Chem, 277:14838-43.
Vijayaraghavan K, Deedwania PC. 2005. The renin angiotensin system as a therapeutic target to prevent diabetes and its complications. Cardiol Clin, 23:165-83.

Vincent MA, Montagnani M, Quon MJ. 2003. Inhibiting NOS blocks microvascular recruitment and blunts muscle glucose uptake in response to insulin. Am J Physiol, 285:E123-30.

Warner FJ, Lubel JS, McCaughan GW, et al. 2007. Liver fibrosis: a balance of ACEs? Clin Sci (Lond), 113:108-18.

Watanabe T, Barker TA, Berk BC. 2005. Angiotensin II and the endothelium: Diverse signals and effects. Hypertension, 45:163-9.

Weber KT. 2001. Aldosterone in congestive heart failure. $N$ Engl J Med, 345:1689-97.

Weir MR. 2007. Effects of renin-angiotensin system inhibition end-organ protection: can we do better? Clin Ther, 29:1803-24.

Wijpkema JS, van Haelst PL, Monraats PS, et al. 2006. Restenosis after percutaneous coronary intervention is associated with the angiotensin-II type-1 receptor $1166 \mathrm{~A} / \mathrm{C}$ polymorphism but not with polymorphisms of angiotensin-converting enzyme, angiotensin-II receptor, angiotensinogen or heme oxygenase-1. Pharmacogenet Genomics, 16:331-7.

Winkelmann BR, Russ AP, Nauck M, et al. 1999. Angiotensinogen M235T polymorphism is associated with plasma angiotensinogen and cardiovascular disease. Am Heart J, 137:698-705.

Wolf G, Ziyadeh FN. 1997. The role of angiotensin II in diabetic nephropathy: enphasis on non-hemodynamic mechanisms. Am J Kidney Dis, 29:153-66.

Yang W, Huang W, Su S, et al. 2007. Association study of angiotensin I converting enzyme 2 gene polymorphisms with coronary heart disease and myocardial infarction in Chinese Han population. Clin Sci (Lond), 111:333-40.

Yki-Jarvinen H. 2003. Non-glycemic effects of insulin. Clin Cornerstone, Suppl 4:S6-12.

Yusuf S, Gerstein H, Hoogwerf B, et al. 2001. Ramipril and the development of diabetes. JAMA, 286:1882-85.

Zaman MA, Oparil S, Calhoum DA. 2002. Drugs targeting the reninangiotensin aldosterone system. Nature, 1:621-36.

Zhong J, Yan Z, Liu D, et al. 2006. Association of angiotensin-converting enzyme 2 gene A/G polymorphism and elevated blood pressure in Chinese patients with metabolic syndrome. J Lab Clin Med, 147:91-5.

Zisman LS, Keller RS, Weaver B, et al. 2003. Increased angiotensin-(1-7)forming activity in failing human heart ventricles: evidence for up regulation of the angiotensin-converting enzyme homologue ACE2. Circulation, 108:1707-12. 
